\title{
Ultrastructural analysis and residual DNA evaluation of rabbit vein scaffold ${ }^{1}$
}

Matheus Bertanha', Marcone Lima Sobreira', Ana Lívia de Carvalho Bovolato", Jaqueline de Carvalho Rinaldi"', Patricia Pintor Reis', Andrei Moroz'v', Leonardo Nazario de Moraes ${ }^{\mathrm{V}}$, Elenice Deffune ${ }^{\mathrm{VI}}$

'Associate Professor, Department of Surgery and Orthopedics, Botucatu Medical School, Universidade Estadual Paulista (UNESP), Botucatu-SP, Brazil. Conception and design of the study, manuscript writing.

"Fellow Master degree, Postgraduate Program in Research and Development (Medical Biotechnology), Cell Engineering Laboratory, Botucatu Medical School, UNESP, Botucatu-SP, Brazil. Conception and design of the study, manuscript preparation.

I'Postdoctoral student, Botucatu Biosciences Institute, UNESP, Botucatu-SP, Brazil. Conception and design of the study, manuscript writing.

"NAssociate Professor, Department of Bioprocess and Biotechnology, School of Pharmaceutical Sciences, UNESP, Araraquara-SP, Brazil. Conception and design of the study, manuscript writing.

${ }^{\vee}$ Fellow PhD degree, Postgraduate Program in Biological Sciences (Genetics), Botucatu Biosciences Institute, UNESP, Botucatu-SP, Brazil. Conception and design of the study, manuscript preparation.

v'Associate Professor, Department of Urology, Botucatu Medical School, UNESP, Botucatu-SP, Brazil. Conception and design of the study, manuscript writing, critical revision.

\section{Abstract}

Purpose: To investigate the ultrastructural characteristics and analysis of residual DNA in scaffold models, produced with decellularized vena cava in an experimental model with rabbits.

Methods: Three groups were created for ultrastructural and residual DNA analysis: group 1 - control, consisting of samples of vena cava in natura; group 2- SD, consisting of vein fragments submitted to $2 \%$ sodium deoxycholate decellularization by shaking (160rpm-Shaker News Brunswick Scientific ${ }^{\circ}$ ) for 1 hour at controlled temperature shaker at $37^{\circ} \mathrm{C}$; group 3 - SDS, consisting of vein fragments submitted to $1 \%$ sodium dodecyl sulfate decellularization under the same previous condition, for 2 hours.

Results: The ultrastructural matrix of the blood vessel maintained its vintegrity after either decellularization models. The results of the two quantification methods demonstrated a significant decrease in the DNA content of the decellularized vena cava samples as compared to the control samples and, differed statistically from each other, $p<0.05$.

Conclusion: The $2 \%$ DS protocol for vein decellularization, in this experimental model, was considered the best protocol because it presented less amount of residual DNA without causing substantial destruction of the extracellular matrix.

Key words: Tissue Scaffolds. Peripheral Arterial Disease. Blood Vessels. Tissue Engineering. Rabbits. 


\section{Introduction}

Cardiovascular diseases continue to be the leader in mortality in western society and its main etiology is atherosclerosis ${ }^{1}$. Some patients have peripheral arterial disease $(P A D)^{2}$. There is, however, a set of patients who develop critical ischemia of the lower limbs, and for some of those endovascular or conventional treatment will not be successful, the remaining option being amputation of the affected limb².

Alternative treatments using tissue engineering may find applications in those cases in particular, with the purpose of producing autologous vessels with specific biomaterials and three-dimensional (3D) structure ${ }^{3,4}$. The initial challenge is to produce a biocompatible scaffold that will provide a microenvironment that imitates natural in vivo tissue architecture for the seeded cells ${ }^{5,6}$. Furthermore, the scaffolds can accomplish many other functions, including facilitating attachment, migration, proliferation, and cell interaction ${ }^{7}$. They must also have enough permeability to allow for nutrients transportion and the elimination of residues ${ }^{7}$.

Alternatives have been searched in order to produce scaffolds, of them being the use of decellularized tissue-derived scaffolds ${ }^{8,9}$. The advantages of this material are related to the essential elements contained in the organic extracellular matrix, such as collagen, fibrinogen, hyaluronic acid, glycosaminoglycans (GAGs), and hydroxyapatite (HA), which is more conducive to cell adhesion and differentiation ${ }^{10}$. Previous experimental studies conducted by this research group have demonstrated that two protocols for decellularization of rabbit vena cava were effective in cell removal and maintenance of the biomechanical characteristics of the 3D scaffold ${ }^{11}$. They were motivated by many articles that describe this technique for other tissues $8,12,13$. For veins, in this model, the best results were obtained using $1 \%$ SDS and $2 \%$ SD, under rapid method ${ }^{11}$.

The ultrastructural evaluation of the scaffolds produced was carried out in order to evaluate the integrity of the extracellular matrix, besides quantifying the residual DNA of the scaffold, in order to be aware of the possibility of the induction of inflammatory response.

\section{- Methods}

\section{Animal housing conditions and tissue harvesting}

Fifteen non-pregnant female adult rabbits (New Zealand) were used for all the experiments. All procedures were conducted respecting the Ethic Guidelines for Animal Experimentation, after the approval by the Brazilian College for Animal Experimentation (CEEA 974/2012). Experiments followed the US National Institutes of Health or European Commission guidelines. Median age of the animals was 4 months and average weight $2.5 \mathrm{~kg}$. All following procedures were conducted under aseptic conditions, after euthanasia with pentobarbital.

The infrarenal inferior vena cava were surgically removed and stored at a sterile HEPES (Sigma- Aldrich ${ }^{\circledR}$ ) supplemented with $100 \mathrm{U} / \mathrm{mL}$ penicillin, $100 \mathrm{mg} / \mathrm{mL}$ streptomycin, and $25 \mathrm{mg} / \mathrm{mL}$ amphotericin B (Invitrogen), stored in a refrigerator at $4^{\circ} \mathrm{C}$ for 24 hours.

\section{Scaffold decellularization}

Three groups were created for ultrastructural analysis: group 1 - control, consisting of samples of vena cava in natura; group 2 - SD, consisting of vein fragments submitted to $2 \%$ sodium deoxycholate decellularization by shaking (160rpm - Shaker News Brunswick Scientific ${ }^{\circledR}$ ) for 1 hour at 
controlled temperature shaker at $37^{\circ} \mathrm{C}$; group 3 - SDS, consisting of vein fragments submitted to $1 \%$ sodium dodecyl sulfate decellularization under the same previous condition, for 2 hours.

All vein fragments were approximately $10 \mathrm{~mm}$ in length, $2.5 \mathrm{~mm}$ in diameter and 5 analysis were done. The scaffolds produced were washed 5 times in PBS phosphate buffer and kept in the refrigerator in sterile HEPES $\left(\right.$ Sigma-Aldrich ${ }^{\circledR}$ ) solution with antibiotic and fungicide at $4 \stackrel{\circ}{ } \mathrm{C}$, for further analysis.

\section{Transmission electron microscopy assay}

The vein samples of the three groups $(n=3)$, as previously described, were submitted to ultrastructural analysis. The samples were fixed overnight by immersion in the Karnovsky's solution. After washing with the same buffer, the samples were post fixed with $1 \%$ osmium tetroxide for $2 \mathrm{~h}$. The material was dehydrated in an increasing acetone series, embedded in Araldite resin (Polysciences, Niles, USA) and $0.5 \mu \mathrm{m}$ thick sections were stained with toluidine blue and prepared for light microscopy in order to choose specific areas for the analysis by transmission electron microscopy ${ }^{14}$. Ultrathin sections were obtained with a diamond knife and contrasted with $2 \%$ uranyl acetate for $30 \mathrm{~min}$, followed by $2 \%$ lead citrate in $1 \mathrm{~N}$ sodium hydroxide solution for $10 \mathrm{~min}$. The samples were analyzed and evaluated using a Tecnai Spirit transmission electron microscope (Fei Company, Oregon, USA), operating at $80 \mathrm{kV}$.

\section{DNA assay}

The vein samples of the three groups $(n=6)$, as previously described, were submitted to residual DNA analysis (control; SD and SDS). The DNA was extracted and eluted in $100 \mu \mathrm{L}$ of ultrapure water using the DNeasy Blood \& Tissue Kit (Qiagen, USA) as recommended by the manufacturer. For quantification of residual DNA two methods were used, the fluorometric and the gel band densitometry. The fluorometric quantification was performed using the Qubit ${ }^{\circledR}$ dsDNA High Sensitivity kit (ThermoFisher, USA) according to manufacturer recommendations and with subsequent reading in the Qubit Fluorometer (ThermoFisher, USA). For band densitometry analysis $0.8 \%$ agarose gel loaded with $4 \mu \mathrm{L}$ of each sample diluted with $3 \mu \mathrm{L}$ loading buffer containing GelX $1 X$ (Biotium, USA) was prepared. In addition to the samples, $4 \mu \mathrm{L}$ of Low DNA Mass Ladder (ThermoFisher, USA) was loaded into the gel under the same conditions. Photo of the gel was captured in grayscale and the DNA band quantified using the ImageJ software ${ }^{15}$. DNA quantification data were normalized by vessel weight. We used the Mann Whitney statistical test, and considered statistically significant $p$-value $<0.05$.

\section{- Results}

Quality control tests were conducted with samples of all vena cava subjected to either decellularization protocols, by conventional histological sections stained in hematoxylin and eosin (HE) and Masson's Trichrome (Figure 1).

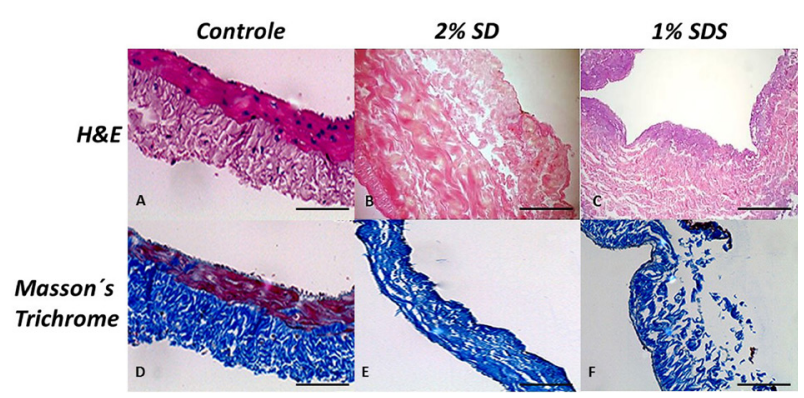

Figure 1 - Representative sections of rabbit blood vessels, stained with H\&E (for general histology), and Masson's trichrome (collagen stains in blue). Generally, all decellularization agents preserved the extracellular matrix structure of the blood vessels in comparison to control vessels. Scale bars $=500 \mu \mathrm{m}$. 


\section{Transmission electron microscopy}

Elastic and collagen fibrils were the extracellular matrix (ECM) components observed in the native rabbit vessels (controls). The collagen fibrils were organized into alternating layers with relative orthogonal orientations between the smooth muscle cells (SMCs). The ultrastructural analysis did not reveal alterations in the features of the vessel matrix, even after treating with $1 \%$ SDS or $2 \%$ SD. The band periodicities of collagen fibrils indicated that a similar spacing between collagen molecules was kept after the decellularization protocols. However, in some areas of the vessels treated with $1 \%$ SDS, collagen fibrils were more loosely packed within collagen fibers and the band periodicities of the fibrils had been lost. No intact nuclei or residual cells were observed in samples subjected to either decellularization protocols, confirming our previous findings that these protocols are efficient in removing cells (Figure 2).

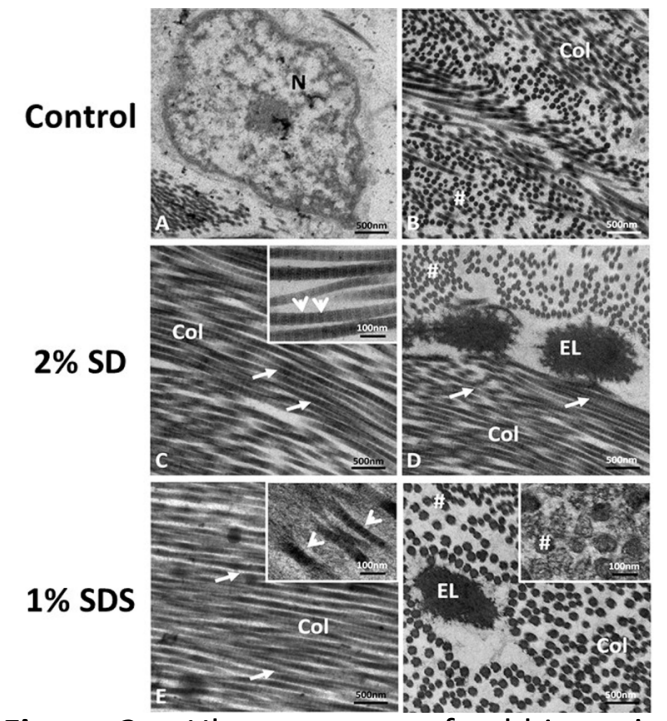

Figure 2 - Ultrastructure of rabbit native vessel (A-B), decellularization treatment with $2 \%$ DS sodium deoxycholate (C-D) and 1\% SDS - sodium dodecyl sulfate (E-F). Arrows reveal collagen fibers that are packed horizontally into thin, straight bundles. N, smooth muscle nuclei; Col, collagen fibrils; E, elastin fibrils; Arrow-heads, transversal striae of collagen fibrils; \# transversal section of collagen fibrils.

\section{$D N A$}

The results of the two methods of quantification demonstrated a significant decrease in the DNA content of the decellularized vena cava samples in relation to the control samples and also differed statistically from each other, $p<0.05$ (figure 2). The mean DNA values found per milligram of vein for fluorometry and band density were: control = $127.66 \mathrm{ng} / \mathrm{mg}, \mathrm{SD}=86.20 \mathrm{ng} / \mathrm{mg}$ and SDS $=107.32 \mathrm{ng} / \mathrm{mg}$; Control $=149.15 \mathrm{ng}$ / $\mathrm{mg}, \mathrm{SD}=73.77 \mathrm{ng} / \mathrm{mg}$ and SDS = $106.82 \mathrm{ng} /$ $\mathrm{mg}$, respectively (Figure 3 ).
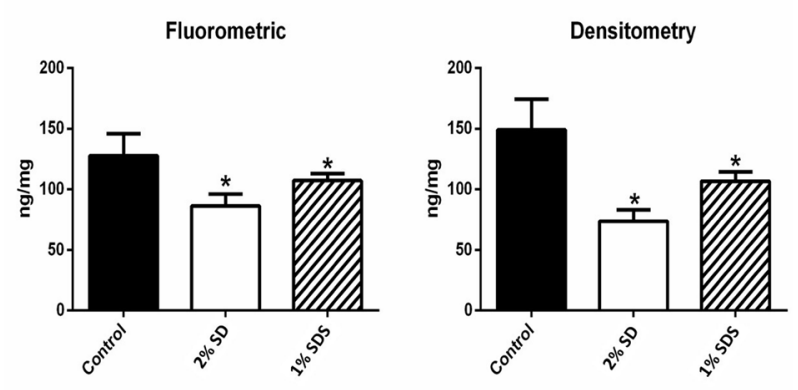

Figure 3 - DNA remaining from decellularized rabbit blood vessel (veins). Control with vein in natura, $2 \%$ SD - sodium deoxycholate; $1 \%$ SDS - sodium dodecyl sulfate. In the left - DNA quantified using fluorometry; In the right - gel band densitometry. Data are expressed as DNA mean in ng per milligram of blood vessel $(\mathrm{ng} / \mathrm{mg}) \pm$ standard deviation. * $p<0.05$ : statistical significance versus control group.

\section{Discussion}

Tissue engineering in blood vessels (TEBV) still remains as a theory that is not fully developed for practical use ${ }^{16}$. Few case reports have shown applications of this technique in humans ${ }^{17}$. Literature has many experimental results for this purpose, but few use veins and even fewer present results related to an ideal venous scaffold. The use of decellularized veins as scaffold was chosen because it 
would facilitate obtaining raw material with application of TEBV techniques in humans, in the future. This is based on the fact that the great saphenous vein is easily obtainable, large in length, and surgically consecrated to be used as vascular grafts, mainly for treatment of more complex cases of $\mathrm{PAD}^{2}$. In addition, the venous scaffolds produced with the techniques described show great similarity with the natural blood vessels, preserving many of the components of the extracellular matrix, as well as maintaining the biomechanical characteristics $^{11}$, what has been proved in our previous studies ${ }^{11}$. Here we were able to demonstrate that two protocols (2\% SD and $1 \%$ SDS) completely removed the cells, minimally damaged the extracellular matrix structure, and removed much of the cellular DNA. Between the two protocols, it was possible to observe that the $2 \%$ SD removed more DNA, therefore it can be inferred that it was more effective in promoting decellularization. Residual DNA in the scaffold can be detrimental to TEBV, since when it suffers phagocytosis during the biointegration process, it could theoretically result in immediate rejection or autoimmune diseases (allogeneic DNA) at any time. However, based on previous studies, we believe that the presence of residual DNA should be less important for tissue engineering than the extracellular matrix degradation ${ }^{18}$ or even the presence of residues DNA neutralizing agents such as DNase (deoxyribonuclease), which may promote further damage to stem cells when seeded. In vivo studies should be performed to better understand the immunological effects of DNA remnants.

\section{- Conclusions}

The methodology of producing scaffolds from the presented experimental model is applicable. Both decellularization protocol, using $2 \%$ SD and $1 \%$ SDS detergent proves more efficient when compared to control, but 2\% SD had lower residual DNA rates as compared to $1 \%$ SDS. Nonetheless, the implementation of additional studies of optimization and quality control will be necessary to guarantee that a minimum DNA presence in acellular scaffolds will not cause problems such as tissue rejection or immune-mediated diseases.

\section{References}

1. Writing $G M$, Lloyd-Jones $D$, Adams $R$, Brown T, Carnethon M, Dai S, De Simone G, Ferguson T, Ford E, Furie K. Heart disease and stroke statistics--2010 update: a report from the American Heart Association. Circulation. 2010;121:e46. doi: 10.1161/ CIRCULATIONAHA.109.192667.

2. Norgren $L$, Hiatt WR, Dormandy JA, Nehler MR, Harris KA, Fowkes FGR, Group TIW. Inter-society consensus for the management of peripheral arterial disease (TASC II). Eur J Vasc Endovasc Surg. 2007;33:S1-75. doi: 10.1016/j.ejvs.2006.09.024.

3. Seifu DG, Purnama A, Mequanint K, Mantovani D. Small-diameter vascular tissue engineering. Nature Rev Cardiol. 2013;10:410-21. doi: 10.1038/ nrcardio.2013.77.

4. CrapoPM, GilbertTW,BadylakSF. Anoverview of tissue and whole organ decellularization processes. Biomaterials. 2011;32:3233-43. doi: 10.1016/j.biomaterials.2011.01.057.

5. Nemeno-Guanzon JG, Lee S, Berg JR, Jo YH, Yeo JE, Nam BM, Koh Y-G, Lee JI. Trends in tissue engineering for blood vessels. J Biomed Biotechnol. 2012;2012:956345. doi: 10.1155/2012/956345.

6. Bertanha M, Moroz A, Almeida R, Alves FC, Valério MJA, Moura R, Domingues MAC, Sobreira ML, Deffune E. Tissue-engineered blood vessel substitute by reconstruction of endothelium using mesenchymal stem cells induced by platelet growth factors. J Vasc Surg. 2014;59:1677-85. doi: 10.1016/j. jvs.2013.05.032.

7. Song Y, Feijen J, Grijpma D, Poot A. Tissue engineering of small-diameter vascular grafts: a literature review. Clin Hemorheol Microcirc. 2011;49:357-74. doi: 10.3233/ CH-2011-1486. 
8. Schaner PJ, Martin ND, Tulenko TN, Shapiro IM, Tarola NA, Leichter RF, Carabasi RA, DiMuzio PJ. Decellularized vein as a potential scaffold for vascular tissue engineering. J Vasc Surg. 2004;40:146-53. doi: 10.1016/j. jvs.2004.03.033.

9. Matsumura G, Isayama N, Matsuda S, Taki K, Sakamoto Y, Ikada Y, Yamazaki K. Long-term results of cell-free biodegradable scaffolds for in situ tissue engineering of pulmonary artery in a canine model. Biomaterials. 2013;34:6422-8. doi: 10.1016/j. biomaterials.2013.05.037.

10.Naderi H, Matin MM, Bahrami AR. Review paper: critical issues in tissue engineering: biomaterials, cell sources, angiogenesis, and drug delivery systems. J Biomater Appl. 2011;26:383-417. doi: 10.1177/0885328211408946.

11.Bertanha M, Moroz A, Jaldin RG, Silva RA, Rinaldi JC, Golim MA, FelisbinoSL, Domingues MA, Sobreira ML, Reis PP. Morphofunctional characterization of decellularized vena cava as tissue engineering scaffolds. Exp Cell Res. 2014;326:103-11. doi: 10.1016/j. yexcr.2014.05.023.

12.Gilbert TW, Sellaro TL, Badylak SF. Decellularization of tissues and organs. Biomaterials. 2006;27:3675-83. doi: 10.1016/j.biomaterials.2006.02.014.

13.Patruno $M$, Martinello T. Treatments of the injured tendon in veterinary medicine: from scaffolds to adult stem cells. Histol Histopathol. 2014;29:417-22. doi: 10.14670/ $\mathrm{HH}-29.10 .417$.

14. Robinson DG, Ehlers U, Herken R, Herrmann $B$, Mayer F, Schürmann FW. Methods of preparation for electron microscopy: an introduction for the biomedical sciences. 1ed. Berlin: Springer-Verlag Science \& Business Media; 1987.

15.Schneider CA, Rasband WS, Eliceiri KW. NIH Image to ImageJ: 25 years of image analysis. Nat Methods. 2012;9:671-5. doi: 10.1038/ nmeth.2089.

16.Niu G, Sapoznik E, Soker S. Bioengineered blood vessels. Expert Opin Biol Ther. 2014 Apr;14(4):403-10. doi: 10.1517/14712598.2014.880419.

17. Olausson M, Patil PB, Kuna VK, Chougule $P$, Hernandez N, Methe K, Kullberg-Lindh C, Borg $H$, Ejnell $H$, Sumitran-Holgersson S. Transplantation of an allogeneic vein bioengineered with autologous stem cells: a proof-of-concept study. Lancet. 2012;380:230-7. doi: 10.1016/S01406736(12)60633-3.

18. Macchiarini $P$, Jungebluth $P$, Go $T$, Asnaghi $M A$, Rees LE, Cogan TA, Dodson A, Martorell J, Bellini S, Parnigotto PP. Clinical transplantation of a tissue-engineered airway. Lancet. 2008;372:2023-30. doi: 10.1016/S0140-6736(08)61598-6.

\section{Correspondence:}

Matheus Bertanha

Departamento de Cirurgia e Ortopedia

Laboratório Vascular

Faculdade de Medicina-UNESP

Avenida Professor Montenegro, s/n Rubião Júnior

18618-687 Botucatu - SP Brasil

Tel.: (55 14)3880-1444

matheus.fameca@ig.com.br

Received: May 16, 2017

Review: July 19, 2017

Accepted: Aug 18, 2017
Conflict of interest: none

Financial source: FAPESP (grant number 2010/52549-8)

\footnotetext{
${ }^{1}$ Research performed at Cell Engineering Laboratory of Blood Transfusion Center, and Department of Surgery and Orthopedics, Botucatu Medical School, Universidade Estadual Paulista (UNESP), BotucatuSP, Brazil.
} 